\title{
EVALUATION OF CLINICAL PROFILE AND OUTCOME OF ABDOMINAL TUBERCULOSIS IN A TERTIARY REFERRAL CENTRE
}

\author{
Sharma A.C.1, Singla Mamta², Gupta Shri Ram³, Jain Shaleen4 \\ ${ }^{1}$ Assistant Professor, Department of Surgery, MMC \& H, Muzaffarnagar. \\ 2 Professor and HOD, Department of Surgery, MMC \& H, Muzaffarnagar. \\ ${ }^{3}$ Senior Resident, Department of Surgery, MMC \& H, Muzaffarnagar. \\ 4Junior Resident, Department of Surgery, MMC \& H, Muzaffarnagar.
}

\begin{abstract}
BACKGROUND

Abdominal tuberculosis is a highly endemic entity. In our country, intestinal tuberculosis is the single largest cause of intestinal obstruction. It has an insidious course, therefore a high index of suspicion is required for an early diagnosis and treatment. Abdominal tuberculosis is managed non-operatively as well as by operative interventions along with ATT (Antitubercular Treatment).
\end{abstract}

Aim of this study:

To define most suggestive clinical features of abdominal tuberculosis.

To evaluate the usefulness of normally available investigations.

To see the response of ATT in abdominal tuberculosis.

To evaluate the usefulness of various operative interventions done for abdominal tuberculosis.

\section{MATERIALS AND METHODS}

This prospective descriptive study of 78 patients, who presented with a clinical diagnosis of abdominal tuberculosis, was conducted in Department of Surgery, Muzaffarnagar Medical College and Hospital, Muzaffarnagar, over a period of one year from May 2015 April 2016. The criteria for diagnosis of abdominal tuberculosis were clinical suspicion, laboratory findings, operative find ings, proven histopathology, demonstration of AFB in specimens and response to antituberculosis drugs. All patients were treated either surgically or non-surgically along with ATT. Patients were followed up for a period of six to twelve months or till death whichever was earlier.

\section{CONCLUSIONS}

The signs and symptoms of intestinal tuberculosis are nonspecific and there are no unequivocal diagnostic features either clinically or radiologically. The most common presenting complaint was abdominal pain (92\%) and the most common sign was abdominal tenderness (69.2\%). Most common age group being the 3 rd decade of life contributing $35.89 \%$ of the total sample size. The most common mode of presentation was that of subacute intestinal obstruction (44\%). The most common site involved was small intestine and ileocaecal region (71.8\%). 48.7\% patients were managed non-operatively and $51.3 \%$ patients were managed operatively. Firstline antitubercular drugs were given to all patients for 6-12 months period. With the aim of saving maximum bowel length, limited resection was performed in $30 \%$ operative cases in the present study, which was second to adhesiolysis (35\%), while only $5 \%$ cases underwent right hemicolectomy. All patients with abdominal tuberculosis responded well to ATT.

\section{KEYWORDS}

Abdominal Tuberculosis, ATT, Adhesiolysis, Right Hemicolectomy, Ileocaecal Region.

HOW TO CITE THIS ARTICLE: Sharma AC, Mamta S, Ram GS, et al. Evaluation of clinical profile and outcome of abdominal tuberculosis in a tertiary referral centre. J. Evolution Med. Dent. Sci. 2016;5(90):6675-6679, DOI: 10.14260/Jemds/2016/1510

\section{BACKGROUND}

Abdominal tuberculosis is a highly endemic entity. It is most common in areas where overcrowding and under nutrition predominate. In our country, intestinal tuberculosis is the single largest cause of intestinal obstruction. Primary tuberculosis of intestine without antecedent or associated pulmonary tuberculosis is fairly common. Abdominal

Financial or Other, Competing Interest: None.

Submission 06-10-2016, Peer Review 31-10-2016,

Acceptance 05-11-2016, Published 09-11-2016.

Corresponding Author:

Sharma A. C,

C-36, Faculty Residences,

Muzaffarnagar Medical College Campus,

Begrajpur, Muzaffarnagar-251203.

E-mail: dracsharma@gmail.com

DOI: $10.14260 /$ jemds $/ 2016 / 1510$

\section{(c) $(1)$}

tuberculosis is one of the most prevalent forms of extrapulmonary disease. After the development of specific drugs, gastrointestinal involvement has decreased from as high as $55 \%-90 \%$ to $25 \%$ in patients with active pulmonary tuberculosis. ${ }^{1}$ Abdominal tuberculosis represents the sixth most frequent form of extra pulmonary tuberculosis after lymphatic, genitourinary, bone and joint, miliary and meningeal tuberculosis. ${ }^{2}$ Abdominal tuberculosis denotes involvement of the gastrointestinal tract, peritoneum, lymph nodes, and solid viscera like liver, spleen, pancreas, etc. The gastrointestinal tract is involved in $65 \%$ to $78 \%$ of patients; associated peritoneal and lymph node involvement is common in these patients. Tuberculosis bacteria reach the gastrointestinal tract via haematogenous spread, ingestion of infected sputum or contiguous spread from adjacent organs. ${ }^{3-}$ 6 Abdominal tuberculosis has an insidious course like any other chronic infectious disease without any specific 
laboratory, radiological or clinical findings. Due to this nonspecificity, there is great difficulty in its diagnosis. Therefore, a high index of suspicion needs to be maintained for an early diagnosis and timely treatment. Abdominal tuberculosis is managed non-operatively as well as by operative interventions.

Antitubercular drugs are given for prolonged periods to all such patients. Perforation is a serious complication of abdominal TB associated with high morbidity and mortality. ${ }^{7}$ ${ }^{9}$ The low incidence of tubercular perforation is due reactive fibrosis of the peritoneum 10-13. However, in recent years, intestinal perforation, which was relatively rare in the past, has been reported more frequently. The cause of this remains unknown. The role of surgery in abdominal tuberculosis is:

1. Diagnostic: For aetiopathological and microbiological diagnosis.

2. Therapeutic: For complications like intestinal obstruction, perforation and peritonitis.

\section{MATERIALS AND METHODS}

This prospective descriptive study was conducted in Department of Surgery, Muzaffarnagar Medical College and Hospital, Muzaffarnagar, over a period of one year from May 2015-April 2016. 78 patients, who presented with clinical diagnosis of abdominal tuberculosis, were enrolled into the study. The criteria for diagnosis of abdominal tuberculosis were clinical suspicion, laboratory findings, operative findings, proven histopathology, demonstration of AFB in specimens and response to antituberculosis drugs. Patient's assessment was done by detailed history, physical examination and relevant investigations. Preoperative investigations included Haemoglobin levels, TLC, DLC, ESR, RBS, LFT, serum electrolytes, urea and creatinine, blood grouping and crossmatching. Patients were also screened for HIV. Radiological investigations included chest $\mathrm{x}$-ray, abdominal $\mathrm{x}$-ray and abdominal ultrasonography. Patients with normal chest $x$-rays but who had symptoms and signs of abdominal tuberculosis were considered to have primary abdominal tuberculosis. Abdominal ultrasound and CT scan were done in some patients suspected to have associated abdominal collections or masses. All patients were treated with Antituberculosis therapy with or without surgery. Intraoperative tissue biopsy was taken for histopathological studies. Final diagnosis and postoperative treatment was dependent on the operative findings and histopathological confirmation. The antituberculosis therapy included Isoniazid, Rifampicin, Pyrazinamide, Ethambutol, with or without Streptomycin. Patients were followed up for a period of six to twelve months or till death whichever was earlier.

\section{RESULTS}

\section{Demographic Profile}

Age Incidence

Age of patients ranged from 7 to 70 years. Most of the cases were in 3rd decade of life making up $35.89 \%$ of the total. Mean age in the present study is 30.57 years \pm 16 yrs.

\section{Gender Incidence}

Out of 78 cases, $36(46.15 \%)$ were males and 42 (53.85\%) were females. M:F ratio was 1:1.16, showing slight preponderance of females which was insignificant.

\section{Symptomatology}

Abdominal pain was the most common presenting symptom in $92 \%$ of cases. Lower abdominal pain was the commonest, followed by periumbilical and generalised abdominal pain. In most cases, pain was described as colicky and intermittent. Other common symptoms were abdominal distention (62\%), altered bowel habits (59\%), fever (67\%), vomiting (56\%), loss of appetite 38\% and weight loss (59\%). Altered bowel habits were found in $59 \%$ of patients, constipation being more common present in $53.84 \%$ cases while diarrhoea was present in $5.12 \%$ cases. Vomiting was present in $56 \%$ of cases and it was followed by relief of pain. Fever was present in $67 \%$ of cases; fever was mild to moderate with evening rise of temperature present in $23 \%$ of cases. Anorexia and weight loss was found in $38 \%$ and $59 \%$ of cases respectively. Most of the cases were having subacute intestinal obstruction with duration of more than one month of complaints. History of night sweats was present in $10 \%$ of cases. Menstrual abnormalities were present in $10.25 \%$ of cases.

\section{Physical Signs}

Abdominal tenderness was the most common finding, found in $(n=54,69.2 \%)$ of cases. Abdominal distention was seen in $48(62 \%)$ cases, which was generalised in $50 \%$ of cases and lower abdominal in $50 \%$ of cases. Guarding, rigidity and rebound tenderness were present in 17 (21.8\%) cases, these were cases of hollow viscus perforation. Mass was found in $14(17.9 \%)$ cases, in 10 cases it was found in right iliac fossa, and in 4 cases in right lumbar region. Hyperperistalsis was found in 14 (17.95\%) cases. Active pulmonary tuberculosis was found in 6 cases, one of them had extensive miliary mottling.

\section{Mode of Presentation}

In the present study, the most common mode of presentation was that of intestinal obstruction, contributing $67 \%$ to the total. Out of these - $23 \%$ cases had acute intestinal obstruction, and rest $44 \%$ had subacute intestinal obstruction, making it the single most common mode of presentation. Mass in abdomen was the mode of presentation in $17.9 \%$ cases. Peritonitis secondary to small bowel perforation, was the diagnosis in $21.8 \%$ of cases. $8 \%$ of cases had pre-op diagnosis of acute appendicitis. The preoperative diagnosis was more accurate in cases with ileocaecal mass and subacute obstruction than in cases that underwent emergency laparotomy for acute intestinal obstruction or perforative peritonitis.

\section{Management \\ Non-operative Management}

Out of 78 cases, 38 cases were managed non-operatively. All responded well to currently used first-line anti-TB drugs. Treatment strategies were based on the guidelines proposed by the CDC of India and the therapeutic regimen consisted of Isoniazid, Rifampicin, Ethambutol, Streptomycin and Pyrazinamide in various combinations for 6-12 months. The mean duration of treatment was $225 \pm 56$ days (range 180360 days). Patients were regularly followed up at our outpatient clinic. The median duration of follow-up was 120 days (range 28-365 days). No relapse was detected during 
the follow-up period. During treatment, four patients experienced adverse drug effects such as jaundice, gastrointestinal upset, skin rashes and peripheral neuropathy. Out of these patients, two died and one was lost to follow-up.

\section{Operative Management \\ Operative Findings}

In the present series of 40 operated cases, most of the cases had multiple findings. Enlarged mesenteric lymph nodes was the most common finding present in 20 cases, ileocaecal thickening was present in 12 cases, caecal thickening with or without ascending colon strictures were present in 5 cases. Pulled up caecum with narrow ileocaecal valve was present in 2 cases. In 6 cases appendicectomy was done and was later diagnosed to be tuberculosis. Small bowel strictures were found in 12 cases, all were in ileum. Small bowel perforation was found in 17 cases, adhesions of small and large intestine were found in 18 cases. Omental thickening was found in 4 cases.

\section{Operative Procedures}

The indication for surgery in most cases was either failure of conservative management, persistent pain with suspicion of tumoural lesion, intestinal obstruction or preoperative diagnosis of intestinal perforation \& generalised peritonitis or preoperative diagnosis of appendicitis. The type of surgical procedure depended upon the site of involvement, severity of pathology, condition of patient and expertise available. Obstructed ileocaecal region was managed by limited resection, right hemicolectomy or a bypass procedure (ileotransverse anastomosis). Strictures, which usually occur in small intestine, were managed by resection and anastomosis or bypass (for tight and scarred strictures).

In cases of perforation, usually with distal strictures, resection and primary repair or resection and ileostomy was performed. In case of adhesions, lysis was done. Biopsy was taken when abdomen was plastered. Most common procedure that was done was adhesiolysis (35\%). Limited (Segmental) resection and anastomosis, including only $5 \mathrm{~cm}$ of ascending colon, was done in $30 \%$ of cases. One case underwent limited resection for sigmoid colon tuberculosis. Right Hemicolectomy was done for $5 \%$ of cases. Small bowel resection and anastomosis was done in $5 \%$ cases due to tight and scarred multiple strictures. Only bypass procedure was done in $20 \%$ cases. In two patients (5\%), only biopsy was taken due to plastered abdomen.

\begin{tabular}{|c|c|c|}
\hline PROCEDURE & $\begin{array}{c}\text { NUMBER } \\
(\mathbf{n = 4 0 )}\end{array}$ & \% \\
\hline $\begin{array}{c}\text { Resections and } \\
\text { Anastomosis (RA) }\end{array}$ & & \\
\hline Limited (segmental) RA & 12 & $30 \%$ \\
\hline Right Hemicolectomy & 2 & $5 \%$ \\
\hline Small bowel RA & 2 & $5 \%$ \\
\hline Stricturoplasty & 0 & $0 \%$ \\
\hline Perforation closure & 0 & $0 \%$ \\
\hline Adhesiolysis & 14 & $35 \%$ \\
\hline Only bypass & 8 & $20 \%$ \\
\hline Only Biopsy & 2 & $5 \%$ \\
\hline \multicolumn{2}{|c|}{ Table 1. Operative Procedures } \\
\hline
\end{tabular}

\section{Pathological Consideration}

In the present series of 78 cases of intestinal tuberculosis, 40 cases were operated and specimens of intestine (including appendix), lymph nodes and peritoneum were available for histopathological diagnosis. Most common pathological diagnosis was that of ulcerative type of intestinal tuberculosis in 26 cases $(33.34 \%)$, of which 10 presented with features of intestinal obstruction and 2 presented with mass per abdomen. Ulcerohypertrophic type of intestinal tuberculosis was found in 14 cases (17.95\%). 1 had jejunal stricture and 9 had ileal strictures. 2 cases presented as appendicitis. Peritoneal involvement was seen in 12 cases (15.39\%), out of which 8 cases $(10.26 \%)$ were of ascitic type and 4 cases (5.13\%) were of fibrous type. Out of 8 cases of ascitic type of peritoneal involvement, 6 were associated with intestinal obstruction and two cases were associated with hypogastric lump. Out of 4 cases of fibrous type of peritoneal involvement, two were associated with intestinal obstruction and two with bowel perforation. 10 cases $(12.82 \%)$ were associated with tuberculosis of mesentery and its contents, out of which 6 (7.69\%) were of bowel adhesions and $4(5.13 \%)$ were of mesenteric adenitis. All of them were associated with intestinal obstruction.

\section{DISCUSSION}

In this series, 78 cases of abdominal tuberculosis with various symptoms and signs were studied. The main focus of this study was the epidemiological observation, clinical manifestation, diagnosis, non-surgical treatment, surgical treatment and outcome of patients with abdominal tuberculosis. The results are analysed in comparison to various studies done on abdominal tuberculosis.

\section{Age Incidence}

In our study, most of the cases were in 3rd decade of life contributing $35.89 \%$ of the total. $36 \%$ cases were in 3 rd decade of life in the Shailesh C et al study ${ }^{\mathbf{1 4}}$, while Ecgleston FC et $\mathrm{l}^{\mathbf{1 5}}$ reported $35 \%$ in the same age group. Bhansali $\mathrm{SK}^{\mathbf{1 3}}$ and MB Islam ${ }^{16}$ et al reported $41 \%$ and $40 \%$ respectively in the same age group.

\section{Symptomatology}

In the present study, abdominal pain was the most common presenting complaint, present in $92 \%$ of cases. This is similar to the findings in a study by Shailesh $\mathrm{C}$ et al14 in which pain in abdomen was the commonest symptom, present in $90 \%$ of cases. In Ecgleston FC et al series, ${ }^{15}$ it was present in $86 \%$ of subjects while in MB Islam et al series, ${ }^{16}$ it was present in $83.3 \%$ of subjects. Abdominal distention was the presenting complaint in $62 \%$ of our cases. Altered bowel habits was the third most significant complaint in the present series, 59\% cases had it as presenting complaint. Ecgleston FC et al15 reported it to be present in $50 \%$ of cases while MB Islam et al 16 reported this presenting symptom in $71.6 \%$ of cases. In both the studies, it was the second most common presenting complaint. The other common symptoms in the present series and series by Ecgleston FC et al15 and MB Islam et al ${ }^{\mathbf{1 6}}$ were abdominal distension, vomiting, mass per abdomen, fever and anorexia with weight loss.

\section{Physical Findings}

In the present study, abdominal tenderness was the most common sign, present in $69.2 \%$ of cases which is similar to the 
study done by Shailesh C et al ${ }^{\mathbf{1 4}}$ where it was present in $56 \%$ of cases, while in Ecgleston FC et al series ${ }^{\mathbf{1 5}}$ it was present in $28 \%$ of cases. Abdominal distension was the second most common finding in the present study, it being present in $62 \%$ of cases, while it was present in $41 \%$ cases in Ecgleston FC et al series 15 ; distension was present in $48 \%$ cases in Shailesh C et al14 study. Mass per abdomen in the present study was present in $12.82 \%$ of cases compared to $26 \%$ in study of Shailesh C et al ${ }^{\mathbf{1 4}}$ while it was present in $14 \%$ of cases in Ecgleston FC et al series. ${ }^{15}$ Other findings like hyperperistaltic bowel sounds, rigidity, guarding, mass in RIF were $17.95 \%$, $38.46 \%, 33.34 \%$ and $5.13 \%$ respectively in this study which are comparable to the $14 \%, 15 \%, 15 \%$ and $10 \%$ in Ecgleston FC et al ${ }^{15}$ series and 18\%, 14\%, 14\% and 2\% in Shailesh C et al14 series.

\section{Diagnosis}

Diagnosis is difficult because of vague symptoms and signs with no pathognomonic investigations. Das and Shukla working in an endemic area reported that diagnosis was made only in $50 \%$ of cases. ${ }^{17}$ Ecgleston $\mathrm{FC}$ et al ${ }^{15}$ reported that preoperative diagnosis was made in $69 \%$ of the cases. In the study by Shailesh $\mathrm{C}$ et al, ${ }^{\mathbf{1 4}}$ correct preoperative diagnosis was made in $60 \%$ of cases. In the present study, correct preoperative diagnosis was made in $54 \%$ of cases. Diagnosis was more often correct in subacute intestinal obstruction or mass per abdomen than in acute obstruction or atypical presentation.

\section{Morbidity and Mortality}

In the present study, operative morbidity was $20 \%$, most common complication being wound infection (15\%). Wound infection is common (Pujari, 1979).18 Ecgleston FC et al15 reported a morbidity of $36 \%$, while MB Islam et al 16 reported a morbidity of $8 \%$. Mortality in the present study was $2.56 \%$ as compared to the Shailesh $\mathrm{C}$ et $\mathrm{al}^{\mathbf{1 4}}$ series where it was $8 \%$. MB Islam et al16 reported mortality lower than the present study, no cases died in their study. In Ecgleston FC et al15 series, it was 3\% in elective surgery and $18 \%$ in emergency, while Bhansali SK ${ }^{13}$ reported it as $2 \%$ and $24 \%$ respectively. Followup with 6-12 months of antitubercular treatment gave excellent results in all patients after surgery in our study.

\section{Operative Management}

When surgery is done, it must suit the pathological findings (Pujari, 1979).18 Limited resection of an ileocaecal mass can be done rather than the classical hemicolectomy because extensive resection of bowel can lead to malabsorption (Prakash et al, 1975). ${ }^{5}$ Strictures can be treated by stricturoplasty (Katariya et al, 1977) ${ }^{19}$ and can be done even in emergency. Perforations are handled by resection rather than over sewing. In the present study of 78 cases, the approach to surgery was conservative. 40 cases underwent surgery of which 30\% underwent limited resection and 5\% underwent right hemicolectomy. As compared to the present study, in Ecgleston FC et al series ${ }^{\mathbf{1 5}}$ 18\% of the cases underwent limited resection, while in $\mathrm{MB}$ Islam et al series ${ }^{\mathbf{1 6}}$ only $10 \%$ underwent limited resection. In Ecgleston FC et al series ${ }^{\mathbf{1 5}}$ and MB Islam et al series, 16 12\% and $63.3 \%$ respectively underwent right hemicolectomy. Stricturoplasty was not done in any patient in present series, while it was done in $36 \%$ cases in Ecgleston FC et al series, 15 while only $3.3 \%$ patients underwent the same procedure in MB Islam et al series. ${ }^{\mathbf{1 6}}$ Only ileotransverse bypass was done in $20 \%$ cases in the present series, while it was done for $18 \%$ cases in Ecgleston FC et al series ${ }^{15}$ and $16.6 \%$ cases in MB Islam et al series. ${ }^{17}$ Bhansali SK ${ }^{13}$ even suggested that bypass patient should be subjected to a secondary excisional procedure when conditions are favourable.

\section{CONCLUSIONS}

\section{A Study was done on 78 Cases. The following Conclusions} were Drawn from the Study

1. The signs and symptoms of intestinal tuberculosis are nonspecific, and there are no unequivocal diagnostic features either clinically or radiologically. The most common presenting complaint was abdominal pain (92\%) and the most common sign was abdominal tenderness (69.2\%). As a result, laparotomy and histopathological examination were frequently necessary to establish confirmatory diagnosis.

2. Most common age group was the $3^{\text {rd }}$ decade of life contributing $35.89 \%$ of the total sample size.

3. Diagnosis of abdominal tuberculosis is difficult in absence of active pulmonary disease. In present study, eight patients had active pulmonary disease and the accuracy of diagnosis was $60 \%$. The most common mode of presentation was subacute intestinal obstruction (44\%). Diagnosis was more difficult in cases of emergency laparotomy. The nature of the obstruction may go unrecognised, particularly in patients having acute symptoms, or caecal masses may be thought to be malignant.

4. The most common sites involved were small intestine and ileocaecal region, in $71.8 \%$ of cases.

5. $48.7 \%$ patients were managed non-operatively and $51.3 \%$ patients were managed operatively. First-line antitubercular drugs were given to all patients for 6-12 months period.

6. The approach to surgery should be conservative, with the aim of saving maximum bowel length, so limited resection was performed in $30 \%$ operative cases in the present study which is second to adhesiolysis (35\%), while only $5 \%$ cases underwent right hemicolectomy.

7. All patients with abdominal tuberculosis responded well to antitubercular treatment (ATT), so all patients should be started on 6 months to 12 months of ATT postoperatively.

\section{REFERENCES}

1. Haddad FS, Ghossain A, Sawaya E, et al. Abdominal tuberculosis. Dis Colon Rectum 1987;30(9):724-35.

2. Kapoor VK. Abdominal tuberculosis: the Indian contribution. Indian J Gastroenterol 1998;17(4):141-7.

3. Kapoor VK. Abdominal tuberculosis. Postgrad Med J 1998;74(874):459-67.

4. Das P, Shukla HS. Clinical diagnosis of abdominal tuberculosis. Br J Surg 1976;63(12):941-6.

5. Prakash A. Ulcero-constrictive tuberculosis of the bowel. Int Surg 1978;63(5):23-9.

6. Horvath KD, Whelan RL. Intestinal tuberculosis: return of an old disease. Am J Gastroenterol 1998;93(5):692-6.

7. Talwar S, Talwar R, Prasad P. Tuberculous perforations of the small intestine. Int J Clin Pract 1999;53(7):514-8. 
8. Seabra J, Coelho H, Barros H, et al. Acute tuberculous perforation of the small bowel during antituberculosis therapy. J Clin Gastroenterol 1993;16(4):320-2.

9. Wig JD, Malik AK, Chaudhary A, et al. Free perforations of tuberculous ulcers of the small bowel. Indian J Gastroenterol 1985;4(4):259-61.

10. Dhar A, Bagga D, Taneja SB. Perforated tuberculous enteritis of childhood: a ten year study. Indian J Pediatr 1990;57(5):713-6.

11. Chaudhary SK. The perforation of tuberculous lesion of the intestine is extremely rare. J Indian Med Assoc 1997;95(2):59-63.

12. Arunabh AS, Kapoor VK, Chattopadhyay TK. Tuberculous perforations of the small intestine. Indian J Tuberculosis 1986;33:190-1.

13. Bhansali SK. Abdominal tuberculosis: experience with 300 cases. Am J Gastroenterol 1971;67(4):324-37.
14. Shailesh C, Nagaraj KN. A study of surgical management of abdominal tuberculosis. Rajiv Gandhi University of Health Sciences, Karnataka, Bangalore 2010:54-69,7481.

15. Ecgleston FC. Surgery in abdominal tuberculosis: results in 137 cases. Ind J Tub 1983;30(4):139-45.

16. Islam $M B$, Rahman $M K$, Islam $M K$, et al. Clinicopathological study of intestinal tuberculosis \& its management. Taj: journal of teachers association 2003;16(1):24-7.

17. Das P, Shukla HS. Clinical diagnosis of abdominal tuberculosis. Br J Surg 1976;63(12):941-6.

18. Pujari BD. Modified surgical procedures in intestinal tuberculosis. Br J Surg 1979;66(3):180-1.

19. Katariya RN, Sood S, Rao PG, et al. Stricture-plasty for tubercular strictures of the gastrointestinal tract. $\mathrm{Br} \mathrm{J}$ Surg 1977;64(7):496-8. 